\title{
Effective Management of Psoriasis (Kalanjagapadai) in Siddha System of Medicine: A Case Report
}

\author{
S. D. Muralidass ${ }^{1 *}$, M. Sendhilkumar ${ }^{1}$, M. V. Mahadevan ${ }^{2}$, V. Mahalakshmi ${ }^{2}$, N. J. Muthukumar ${ }^{2}$
}

${ }^{1}$ Siddha Physician \& Independent Researcher, Chennai, Tamil Nadu-600106, India

${ }^{2}$ Department of Sirappu Maruthuvam, National Institute of Siddha, Tambaram Sanatorium, Chennai, Tamil Nadu-600047, India

DOI: $10.36347 /$ sjmcr.2020.v08i09.012

| Received: 04.09.2020 | Accepted: 14.09.2020 | Published: 17.09.2020

*Corresponding author: Dr. S. D. Muralidass

Abstract

Case Report

Psoriasis is a chronic, multisystem inflammatory disease with predominantly skin and joint involvement. In addition to genetics and altered immune function, several other risk factors may predispose patients to psoriasis such as environmental triggers, medications, psychogenic stressors. A 50-year-old woman was admitted in National Institute of Siddha (NIS) with a severe form of Psoriasis. The patient suffering by hyper-pigmented patches with scaling occurred all over the body. Based on the report and clinical examination the physicians diagnosed this was a Psoriasis. The patient used to get admitted every year due to the aggravation of symptoms. She was recovered completely from all the symptoms by Siddha Internal Medications 'Rasagandhi Mezhugu, Palagarai Parpam, Parangippattai Chooranam and Sangu Parpam' and Siddha External Medications 'Arugan Thailam, Pungan Thailam and Vatha Kesari Thailam'. This case report indicates that Psoriasis can be well treated with Siddha medicines.

Keywords: Siddha, Erythrodermic Psoriasis, Skin diseases, Kalanjagapadai, Kuttam.

Copyright @ 2020: This is an open-access article distributed under the terms of the Creative Commons Attribution license which permits unrestricted use, distribution, and reproduction in any medium for non-commercial use (NonCommercial, or CC-BY-NC) provided the original author and source are credited.

\section{INTRODUCTION}

Psoriasis is a chronic, multisystem inflammatory disease with predominantly skin and joint involvement. Beyond the physical dimensions of disease, psoriasis has an extensive emotional and psychosocial effect on patients, affecting social functioning and interpersonal relationships. The cause of the disease is not known, but it is believed to be an auto-immune disease. Approximately $15 \%$ of Psoriasis patients may subsequently develop Psoriatic arthritis, a potentially debilitating joint condition $[1,2]$. The precise pathologic mechanisms that drive the development of Psoriasis are extremely complex. However, recent insights into its path physiology have enabled a better understanding of the disease and revealed potential new therapeutic targets [3]. In addition to genetics and altered immune function, several other risk factors may predispose patients to psoriasis such as environmental triggers, medications, psychogenic stressors. There are six common Psoriasis types. These are Plaque Psoriasis, Pustular Psoriasis, Guttate Psoriasis, Nail Psoriasis, Erythrodermic Psoriasis, and Inverse Psoriasis $[4,5]$.

It is a well-known fact that Traditional Systems of medicines always played an important role in meeting the global health care needs. India is known for its traditional medicinal systems-Ayurveda, Siddha, and Unani. Medical systems are found mentioned even in the ancient Vedas and other scripture. Siddha system of medicine is practiced in some parts of South India especially in the state of Tamilnadu. It has close affinity to Ayurveda yet it maintains a distinctive identity of its own. This system has come to be closely identified with Tamil civilization $[6,7]$. Siddha medicine formulations are mostly polyherbal, but also include metals, minerals, and animal products. The common Siddha preparations are Parpam(calcined metals and minerals), Chooranam (Powders), Kudineer (Decoctions), Legiyam (Confections), Ghritam (Ghee), Tailam (Oil), and Mezhugu (Wax). The system includes principles of positive health and therapeutic measures relating to Physical, Mental, Social and Spiritual welfare of human beings [8]. The Siddha medicine treatment show positive results on controlling many communicable and non-communicable diseases. The Skin disorders are brought under the clinical entity "Kuttam" in Siddha system. In Siddha, Psoriasis is termed as Kalanjagapadai (Synonyms: SedhilUdhirPadai, SambalPadai, VenparuSedhil, SedhilUdhirNoi) and describing the Kalanjagapadai as a chronic, non infectious, recurrent, inflammatory disorder of the skin 
characterized by reddish, slightly elevated patches covered with silvery white scales [9].

\section{Patient Information}

A 50-year-old woman from Jharkhand, India was admitted at In-Patient Ward in National Institute of Siddha (NIS), Tambaram, Chennai in the month of August 2012. The patient had severe form of Psoriasis (Figure $1 \& 2$ ). The symptoms were hyper-pigmented patches with scaling, red patches of skin covered with thick, silvery scales, Small scaling spots, cracked skin and itching all over the body for 3 months and pricking pain and watery discharge, constipation, body pain, joint pain for the last 15 days. The sign and symptoms are used to get aggravated very fast in a very short period. She had to be admitted for treatment previously during the aggravated period. The patient was suffering this problem every year. She was also under medication for Hypothyroidism for more than 10 years. The associated co-morbidities such as psoriatic arthritis and depression were also found during the examination. The patient was treated with Systemic antibiotics, Corticosteroids, Immune suppressants, and Nonsteroidal anti-inflammatory drugs. Based on the report and clinical examination the physicians diagnosed this was Psoriasis. The skin biopsy was done to diagnose this disease. The physicians diagnosed this as severe form of Psoriasis as Body Surface Area (BSA) covered more than $10 \%$ in the body.

\section{Diagnosis in Siddha System and Assessment}

The Siddha physicians at National Institute of Siddha were used Siddha system diagnostic methods such as Kaalam (Season), Nilam (Land) and Kutram (Body three humors). Based on the Siddha diagnosis, the patient from Kurinjinilam (mountains and adjoining lands), admitted in Munpanikalam (winter season) and her physique is Kabhapitham (one of the Siddha physical constitution). All the Siddha clinical parameters were examined and the finalized as the following Siddha parameters of the patient were affected: Mei (Skin - Patches), the Abanan (Division of Vaatham - Constipation), Viyanaan (Type of Vaatham Itching and scaling), Samanan (Type of Vathamaffected andimbalance of the Vaatham), Saaram (Chyle - Depression), Sennner (Blood - Pallor) and Oon (Muscle - Pain in knee joints) Niram (Colour Erythema), Malam (Faeces - Constipation), Naadi (Siddha Pulse - Pithakabham), Sparisam (Skin - Itching and scaling) [10]. The treatment regimen was started based on the Siddha diagnostic methods and Siddha philosophy. The treatment initially started with purgative to reduce the Vaatham in the body then internal and external medicines were provided. There was a gradual improvement in the skin lesions within week's (Figures 3 and 4). The scales started shedding and Papular lesions converted into macules, itching also decreased gradually after treatment started. The internal and external medicine of the Siddha system of Medicine which was used for treatment mentioned in the Table-1. The medicines were prescribed for further follow-ups.

Table-1: Details of Siddha Treatment Provided To the Patient

\begin{tabular}{|c|c|c|}
\hline Days & Internal medicines & External applications \\
\hline Day1 & Agathiyarkuzhambu with hot water at early morning for purgation & Nil \\
\hline Day 2 & Nil & Nil \\
\hline Day 3-15 & $\begin{array}{l}\text { RasagandhiMezhugu Capsule- } 2(100 \mathrm{mg}) \text {-twice a day with palm jaggery after food } \\
\text { Parangippattai Chooranam-Tablet-2 }(500 \mathrm{mg}) \text { thrice a day with milk after food } \\
\text { PalagaraiParpam Tablet }-2(100 \mathrm{mg}) \text { thrice a day with milk after food } \\
\text { Nilavembukudineer }-60 \mathrm{ml} \text { twice a day after food }\end{array}$ & $\begin{array}{l}\text { AruganThailam and } \\
\text { PunganThailam for local } \\
\text { application twice a day }\end{array}$ \\
\hline Day 16-31 & $\begin{array}{l}\text { RasagandhiMezhugu Capsule }-2(100 \mathrm{mg}) \text {-twice a day with palm jaggery after food } \\
\text { Parangippattai Chooranam-Tablet-2 }(500 \mathrm{mg}) \text { thrice a day with milk after food } \\
\text { PalagaraiParpam Tablet }-2(100 \mathrm{mg}) \text { thrice a day with milk after food } \\
\text { SanguParpam Tablet }-2(100 \mathrm{mg}) \text { thrice a day with milk after food } \\
\text { NilavembuKudineer - } 60 \mathrm{ml} \text { twice a day after food }\end{array}$ & $\begin{array}{l}\text { Aruganthailam and } \\
\text { Punganthailam for local } \\
\text { application twice a day } \\
\text { VadhaKesariThailam for } \\
\text { knee and joint pains }\end{array}$ \\
\hline
\end{tabular}

Table-2: Actions of the Prescribed Drugs and Its Dosage Level

\begin{tabular}{|l|l|l|l|}
\hline S. No & Name of the drugs & Actions & Usage \\
\hline 1 & $\begin{array}{l}\text { RasagandhiMezhugu } \\
\text { Capsule }\end{array}$ & $\begin{array}{l}\text { All chronic diseases. Eczema, Psoriasis, early } \\
\text { stages of Cancer and Leprosy }\end{array}$ & $\begin{array}{l}2 \text { (100mg)-twice a day with palm } \\
\text { jaggery after food }\end{array}$ \\
\hline 2 & ParangippattaiChooranam & $\begin{array}{l}\text { Useful in all skin diseases. It promotes appetite } \\
\text { and gives the complexion to the skin. }\end{array}$ & $\begin{array}{l}1 \text { to } 3 \text { gms with honey or milk every } \\
\text { day. }\end{array}$ \\
\hline 3 & PalagaraiParpam & $\begin{array}{l}\text { Vitalizer and hemostatic. Used in allergic } \\
\text { diseases, cough, and bronchitis. }\end{array}$ & 100 to 200 mgs every day. \\
\hline 4 & SanguParpam & $\begin{array}{l}\text { Useful in the Gastric ulcer, pain in stomach and } \\
\text { duodenum, also for calcium deficiency disorders. }\end{array}$ & 100 to 300 mgs, every day. \\
\hline 5 & NilavembuKudineer & Useful in Fever and Autoimmune disease. & 30 to 60 ml every day. \\
\hline 6 & PunganThailam & $\begin{array}{l}\text { Useful in Chronic ulcers, Wound, and Skin } \\
\text { Diseases. }\end{array}$ & $\begin{array}{l}\text { External application only. Apply } \\
\text { freely, frequently as much as } \\
\text { required. }\end{array}$ \\
\hline
\end{tabular}




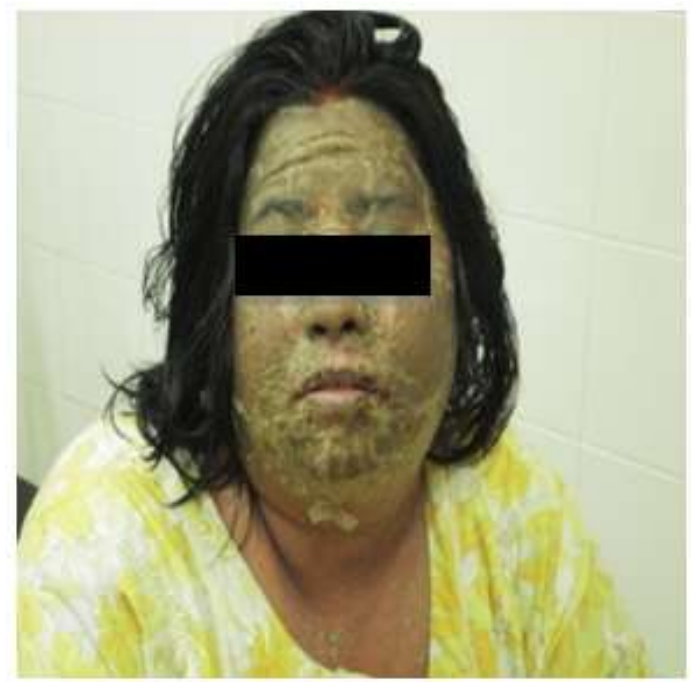

Fig-1: Erythematous plaques on the face before treatment

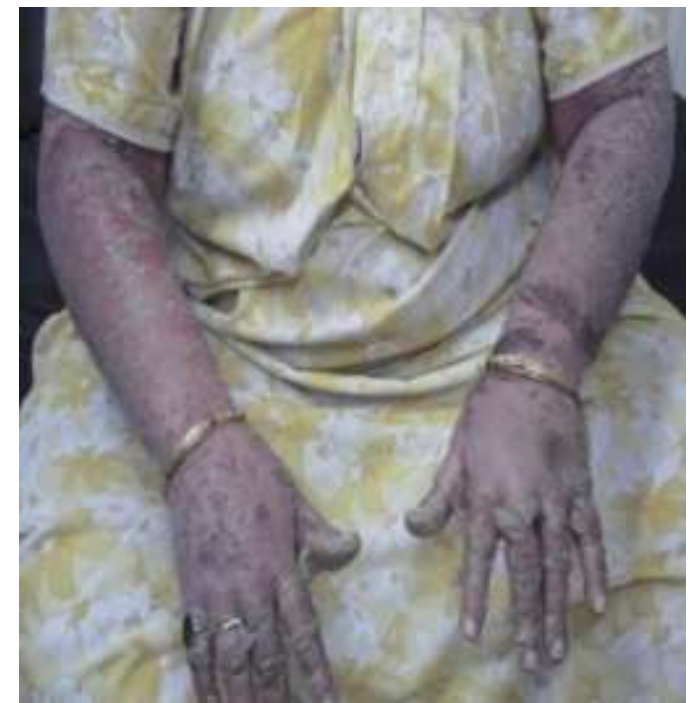

Fig-2: Erythematous plaques on both hands before treatment

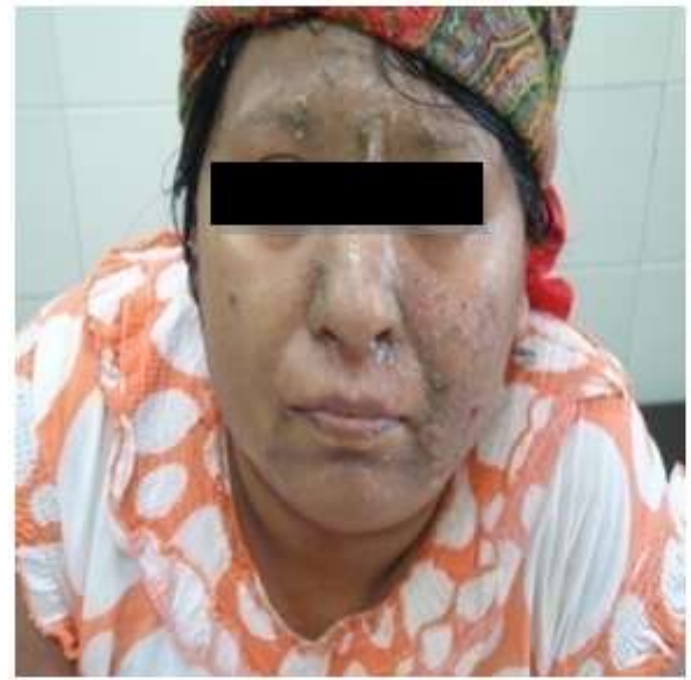

Fig-3: Erythematous plaques on the face during treatment

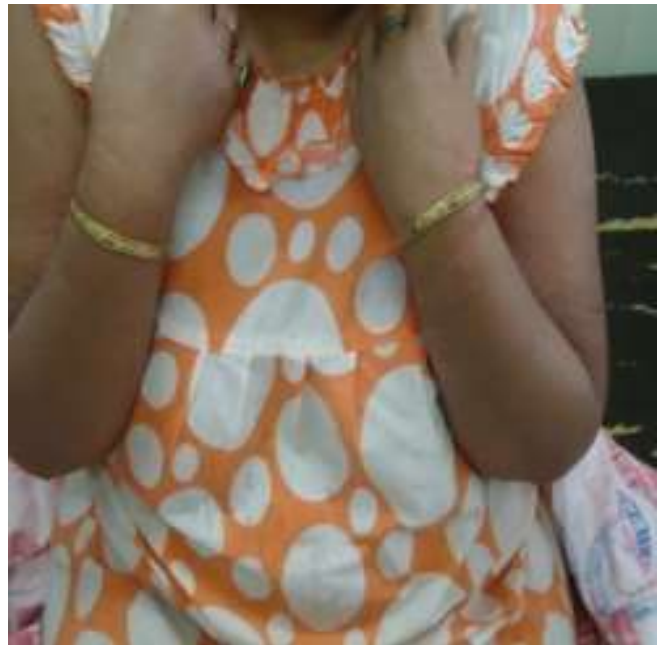

Fig-4: Erythematous plaques on hands during treatment

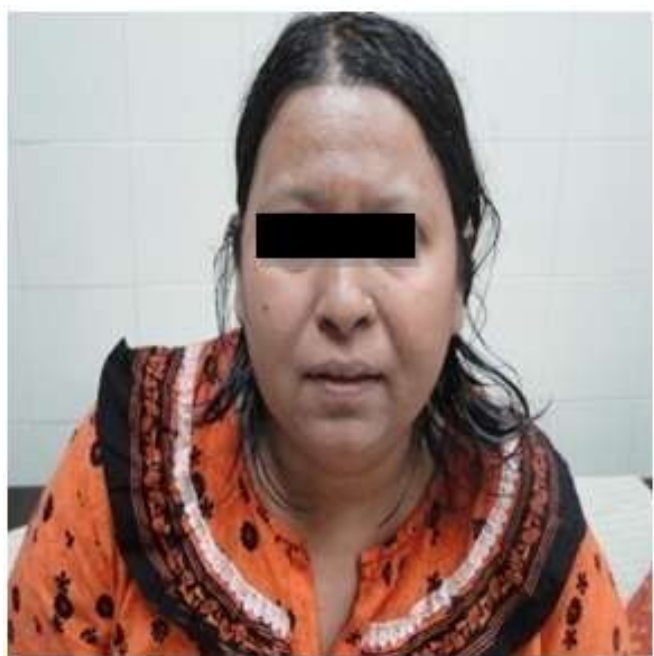

Fig-5: Erythematous plaques on the face after treatment

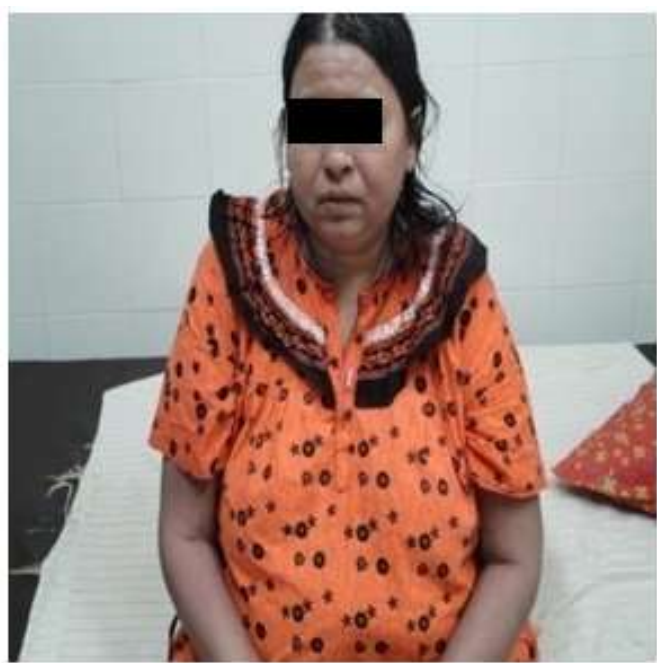

Fig-6: Erythematous plagues on handsafter treatment

\section{DISCUSSION}

Conventional (allopathic) drugs are used to treat various auto-immune disorders. The alternative and complementary systems such as Ayurveda and Siddha show that it has positive impact on auto-immune 
disorders such as Psoriasis. We had started with Agathiyarkuzhambu (Purgative) with hot water at early morning. This purgative was used to reduce the Vaatham in the body and increase the absorption of the medicines. No medicine was provided to the patient on the second day as the patient had to take rest after purgative. The internal and external medicines were suggested from third day onwards. Indian System of Medicines are involved in the curative and preventive measures to promote the health. Traditional medicine particularly herbal medicine playing important role in maintain of health. Inclusion of traditional herbal medicine in clinical practice will help to achieve the target 'health for all'. Therefore, mainstreaming of Indian System of Medicines (ISM) along with allopathic drugs and healthy lifestyle will be helpful to provide healthcare service in best possible way to all people not only in India but around the globe.

The patient signs and symptoms were reduced drastically after intake of Siddha medicines. The previous studies show that RasaganthiMezhugu, ParangipattiChooranam, SanguParpam and PalagaraiParpamhave positive impact on treating Skin diseases [11, 12]. The patient got significant relief of the joint pain and general body ache also. The physical and mental health also improved during this treatment as her symptoms were reduced (Figures $5 \& 6$ ). The patient admitted one month in the hospital. After successful management of the kalanjagapadai in the hospital, the patient was advised to take medicines two more months for follow up and for preventive measure. Use and action of the prescribed drugs are mentioned in the Table-2.

\section{CONCLUSION}

This patient's signs and symptoms, mental well being improved significantly after treatment started without any complications. This case study signifies that the application of Siddha treatments on Psoriasis is effective. A follow-up large sample study will be important to assess the efficacy of given Siddha treatment protocol.

\section{Financial support and sponsorship: Nil}

\section{Conflicts of interest: There are no conflicts of interest}

\section{REFERENCES}

1. Canadian Psoriasis Guidelines Committee. Canadian guidelines for the management of plaque psoriasis. Ottawa, ON: Canadian Dermatology Association; 2009.
2. Menter A, Gottlieb A, Feldman SR, Van Voorhees AS, Leonardi CL, Gordon KB, Lebwohl M, Koo JY, Elmets CA, Korman NJ, Beutner KR. Guidelines of care for the management of psoriasis and psoriatic arthritis: Section 1. Overview of psoriasis and guidelines of care for the treatment of psoriasis with biologics. Journal of the American Academy of Dermatology. 2008 May 1;58(5):826-50.

3. Cohen BA. Papulosquamous eruptions. InPediatric Dermatology (Fourth Edition) 2013. 68-103).

4. Suárez AL, Feramisco JD, Koo J, Steinhoff M. Psychoneuroimmunology of psychological stress and atopic dermatitis: pathophysiologic and therapeutic updates. Actadermato-venereologica, 2012; 92(1):7-15.

5. Psoriasis: Symptoms, Causes, Locations National Psoriasis Foundation [Internet]. Psoriasis.org. 2019 [cited 17 February 2019]. Available from: https://www.psoriasis.org/about-psoriasis

6. Introduction and Origin Ministry of AYUSH GOI [Internet]. Ayush.gov.in. 2018 [cited 23 October 2018]. Available at: http://ayush.gov.in/about-thesystems/siddha/introduction-and-origin

7. Narayanaswamy V. In: Introduction to the Siddha System of Medicine. T. Nagar, Madras (Chennai): Research Institute of Siddha Medicine; 1975.

8. Central Council of Indian Medicine (CCIM) [Internet]. 2018 [cited 23 October 2018]. Available from: https://www.ccimindia.org/siddha.php

9. Vaidhayashala T. Siddha Medicine for Psoriasis: Causes, Treatment \& Cure Natural Way. - TKN Siddha Ayurveda Vaidhyashala (Hospital) [Internet]. TKN Siddha Ayurveda Vaidhyashala (Hospital). 2018 [cited 23 October 2018]. Available from: http://www.tknsiddha.com/medicine/psoriasistreatment/

10. Shanmugavelu M. NoinaadalnoimuthalnadaalThirattu- Part I -Third edition. 2003.

11. National Institute of Siddha, Chennai, IN Rediscovering Siddha treatment for Psoriasis (Kalanjagapadai) with Gandhaga Mezhugu a Siddha Herbo Mineral formulation - A Success story Nischennai.org. 2018 [Accessed 25 October 2018]. Available at: http://nischennai.org/siddhasuccess-stories-nis-psoriasiskaalaanjagapadai.html

12. Health \& Family Welfare Department, Govt. of Tamil Nadu. Tnhealth.org. 2018 [Accessed 25 October 2018]. Available at: http://www.tnhealth.org/directorate/imtmpl.html. 